\title{
THE WORLDWIDE USE OF COMPUTERS: A DESCRIPTION OF MAIN TRENDS
}

\author{
Willem J. Pelgrum and Tueerd Plomp \\ Department of Education, University of Twente, Enschede, The Netherlands
}

(Received 7 October 1992; revised 2 March 1993; accepted 7 May 1993)

\begin{abstract}
This paper examines some of the main findings from the IEA Computers in Education survey. The results show that with respect to the future of computers in education there is reason for optimism as well as for pessimism. The optimistic part of the story is that new technologies in the form of computers are nowadays available for many schools in most so-called developed countries, and that despite the complexity of this innovation educational practitioners and students are still very enthusiastic about this technology. The pessimistic part is that there is still much inequity of access to computers. Once computers are available they tend to be used most frequently as an add-on to the existing curriculum. It is probably this lack of integration of computers in existing curricula which is most challenging in determining our agenda for the future.
\end{abstract}

\section{INTRODUCTION}

In the 1980 s, computers were introduced gradually into schools in most developed countries. Computer projects were started at the higher educational levels but quite quickly they also penetrated the secondary and lower elementary levels. They were often backed by governments with the argument that the technology might be a catalyst for development, even in countries where basic materials like chalk, paper and pencils were frequently lacking $[1,2]$.

Even without government support, the push to adopt the new technology was so great that many schools acquired computers on their own or with the support of local banks and industry. For example, before the start of The Netherlands government programme to introduce computers in elementary schools, half had already acquired equipment of their own. Although it appears superficially that these innovations were non-controversial, in practice the picture was very different: the use and application of computers is complex, expensive, beset with problems, and demands a great investment of time from educational practitioners. Above all, it was not clear what were the goals of such innovation.

These findings stem from an international survey, conducted under the auspices of the International Association for the Evaluation of Educational Achievement (IEA) in which 22 countries participated and which was conducted in 1989. This paper examines some of the main findings from this Computers in Education (Comped) survey. Other results of the study have been published [3,4].

\section{THE INTERNATIONAL ASSOCIATION FOR THE EVALUATION OF EDUCATION ACHIEVEMENT}

The IEA is a non-governmental international organization of professional educational research workers from 44 countries[5]. The organization has been in existence for more than 30 years. The IEA researchers undertake international comparative research projects in core school subjects like mathematics, science and mother tongue.

In general, the design of IEA studies involves collecting data at different levels of the school system, country, school, teacher and student. National representative samples are taken from usually three populations of students, near the end of primary education, the first stage of secondary education and the second stage of secondary education. As can be learned from IEA reports, the publications are aimed at various audiences but the general goal is to promote understanding of the functioning of education to contribute to its improvement $[6,7]$. 


\section{THE IEA COMPUTERS IN EDUCATION SURVEY}

The major goals of the study were to describe and analyse cross-nationally as well as longitudinally how computers are used in schools by teachers and students, and what cognition, skills and attitudes students have with respect to new information technologies. The study consisted of two stages. During stage 1 (1987-1990) data were collected in 1989 in elementary, lower secondary and upper secondary schools at school and teacher level. In stage 2 (1991-1994) measures from stage 1 will be repeated and, in addition, measures at student level will be taken.

The measures taken in stage 1 of the study were based on a conceptual framework characterizing the educational system in terms of levels of decision-making at the macro-, meso-, and micro-level and identifying the factors contributing to changes [3]. These factors were taken from literature on educational change [8] such as the quality, clarity and relevance of the objectives and the characteristics of the innovation, content, materials and instructional strategies; support and leadership; staff development; experiences with innovations; and the existence of evaluation and feedback. The framework reflects the hierarchical structure of most educational systems, but acknowledges that decisions which promote or inhibit the implementation of computer-related curricula are made at all levels, which may cause discrepancies between decisions and expectations that exist at the different system levels. An identification of these discrepancies may in itself be an important starting point for improvement measures in education.

In stage 1 , data were collected by means of questionnaires from about 60,000 respondents, principals, computer coordinators and teachers, from schools sampled in the following 21 education systems. They are listed with acronyms to be used in the remainder of this paper: AUT: Austria; BFL: Belgium-Flemish; BFR: Belgium-French; CBC: Canada British Columbia; CHI: China; FRA: France; FRG: Federal Republic of Germany; GRE: Greece; HUN: Hungary; IND: India; ISR: Israel; ITA: Italy; JPN: Japan; LUX: Luxembourg; NET: The Netherlands: NWZ: New Zealand; POL: Poland; POR: Portugal; SLO: Slovenia; SWI: Switzerland; USA: United States of America.

\section{THE GOALS OF INTRODUCING COMPUTERS IN EDUCATION}

The introduction of computers in education is an educational change of unprecedented nature. One factor which is very important in implementing a change is the clarity of goals and means [9].

"Unclear and unspecified changes can cause great anxiety and frustration to those sincerely" trying to implement them" (Fullan and Stiegelbauer [9, pp. 70-71]).

Therefore, to interpret how computers are used in educational practice, the question must be posed "What is one trying to achieve?" This question can be tackled from different perspectives. Theoretically, one may point to the many potential goals that have been put forward in the literature. From a more practical perspective one may look at legislation and curriculum guidelines and/or the perceptions/expectancies of educational practitioners.

One problem often associated with program guidelines is that they suffer from vagueness, often reflecting compromises between parties involved. Typically with regard to the introduction of computers one often finds goals described in terms of

"Economical and vocational training for the computer-age" (Austria),

"Improve efficiency in instruction" (Israel),

...the need for school education to properly respond to the rapid transition of the society which is moving toward highly information-oriented society" (Japan); (source: IEA-Comped National Questionnaires).

With regard to computers in education, the setting of goals has proved to be difficult in the past decade, probably because of the newness of the domain. We had to conclude that the top-down perspective in the Comped study did not produce operational data. An alternative approach may be to take a bottom-up perspective by looking at the implicit goals or expectancies of educational practitioners, who have adopted the new computer technology. 
In the IEA-Comped study, information has been collected regarding these implicit goals[3]. If school principals are asked about the importance of different reasons for introducing computers in their school, one finds that the primary reason, from elementary to upper secondary schools, was "to provide experience for the future". Davis[10] points out that:

"this finding is interesting in that it indicates a lack of specificity ... which may indicate a lack of direction from above". Other non-instrumental reasons like "keeping the curriculum up to date" and "teachers were interested" are also cited very frequently, especially in secondary schools. In elementary schools instrumental reasons like "improving achievement" and "individualized learning" are cited quite frequently.

From the attitude parts of the questionnaires to school principals and teachers, it is clear that educational practitioners have high expectations from computers. Pelgrum and Plomp[3] show that educational practitioners in most countries have very positive attitudes about the educational impact of computers, in terms of expectations about improving student achievement and educational productivity. The data also show that improved educational outcomes is not only an expectation, but that teachers seem to think they observed positive changes as a result of using computers: respectively 69,61 and $52 \%$ of the teachers of mathematics, science and mother tongue in lower secondary schools in the USA sample indicated that they observed an increased availability of feedback about student achievement, an increased interest of students, and increases in student achievement. Pelgrum and Plomp[3] found similar results in other countries.

So, from these results one may infer that, although schools usually start with using computers for unspecific reasons, more implicitly they expect that the quality of education may be improved. This last aspect is important, because it relates to one of the more theoretical claims about the pedagogical strength of computers namely

"more active learning, more varied sensory and conceptual modes, individually tailored learning, learning nearer the speed of thought, and an aid to abstraction" (Walker[11, p. 23]).

This presupposes that computers are fully integrated in the learning activities of students, which is one of the central perspectives in the current wave of thinking about multimedia.

\section{IMPLEMENTATION OF COMPUTERS}

The most crucial question regarding the implementation of computers is: "How are computers actually used by teachers and students?", and related to this: "Are computers used as they should be used?". Although we already indicated above that this last question is difficult to answer, because specifications of intended computer use are often lacking in countries, the prevailing impression is that a profound analysis of this question did not have a high priority in the mind of those who were involved in implementing this innovation. Rather it seems that there has been an over-emphasis on the provision of hardware and software at the cost of a relative neglect of other important conditions for implementing computers in schools. As it is difficult to talk about the type of use without discussing accessibility and availability of hardware and software, we will first present some descriptive results regarding these aspects.

\section{Access to computers}

As indicated in Table 1, the data from stage 1 of the IEA Computer in Education study show that in most countries which participated in the study, a majority of lower and upper secondary schools used computers for instructional purposes, while this is the case to a lesser extent in elementary schools. From the median student:computer ratios one may infer that, in general, the accessibility of computers within schools was far from ideal in 1989. In addition to that, one should realize that in most countries the majority of hardware consisted of 8-bit machines.

\section{Access to software}

The IEA survey contained a number of questions about the availability of software in the schools. The computer coordinators were asked to check which of 23 types of software was available in the school. 
Table 1. Per cent of schools using computers for instructional purposes and median student: computer ratios

\begin{tabular}{|c|c|c|c|c|c|c|}
\hline \multirow[b]{3}{*}{$\begin{array}{l}\text { Country/educational } \\
\text { system }\end{array}$} & \multicolumn{6}{|c|}{ Per cent use } \\
\hline & \multicolumn{2}{|c|}{ Elementary } & \multicolumn{2}{|c|}{ Lower secondary } & \multicolumn{2}{|c|}{ Upper secondary } \\
\hline & $\begin{array}{l}\text { Per cent } \\
\text { using } \\
\text { computers }\end{array}$ & $\begin{array}{c}\text { Median } \\
\text { student/ } \\
\text { computer } \\
\text { ratio }\end{array}$ & $\begin{array}{l}\text { Per cent } \\
\text { using } \\
\text { computers }\end{array}$ & $\begin{array}{c}\text { Median } \\
\text { Student } \\
\text { computer } \\
\text { ratio }\end{array}$ & $\begin{array}{l}\text { Per cent } \\
\text { using } \\
\text { computers }\end{array}$ & $\begin{array}{c}\text { Median } \\
\text { Student } \\
\text { computer } \\
\text { ratio }\end{array}$ \\
\hline Austria & - & - & 62 & 29 & 100 & 26 \\
\hline Belgium-Flemish & - & -- & 78 & 28 & 98 & 35 \\
\hline Belgium-French & 54 & 28 & 93 & 34 & 93 & 38 \\
\hline Canada-British Columbia & 99 & 21 & 100 & 12 & 100 & 12 \\
\hline China & - & - & - & - & 61 & 43 \\
\hline France & 92 & 23 & 99 & 31 & 99 & 27 \\
\hline Federal Republic of Germany & - & - & 94 & 47 & 100 & 48 \\
\hline Greece & - & - & 5 & 52 & 4 & 44 \\
\hline Hungary & - & - & - & - & 100 & 27 \\
\hline India & - & - & - & - & 7 & 95 \\
\hline Israel & 62 & 17 & - & - & 82 & 29 \\
\hline Italy & 43 & 116 & 58 & 90 & 80 & 36 \\
\hline Japan & 25 & 14 & 36 & 143 & 94 & 32 \\
\hline Luxembourg & - & - & 100 & 48 & - & - \\
\hline The Netherlands & 53 & 64 & 87 & 26 & 69 & 34 \\
\hline New Zealand & 78 & 62 & 99 & 34 & 100 & 38 \\
\hline Poland & - & - & - & - & 72 & 53 \\
\hline Portugal & 29 & 301 & 53 & 287 & 72 & 289 \\
\hline Slovenia & - & - & - & - & 94 & 50 \\
\hline Switzerland & - & - & 74 & 21 & 98 & 21 \\
\hline United States of America & 100 & 23 & 100 & 18 & 100 & 15 \\
\hline
\end{tabular}

- = data not collected.

This list together with the boxplots of the percentages of computer coordinators across countries indicating that a particular type of software was available in the school is presented in Fig. 1 for cach cducational level.

Figure 1 shows that there is considerable variation with respect to the availability in schools of particular types of software. The medians show that educational tool software (drill/practice, tutorial and educational games) as well as general purpose programs (word processing and database programs) are in the top 10 of available types of software in all populations. There is a clear difference between elementary education, with drill/practice and educational games at the top, and secondary education, with general purpose and programming languages at the top. Furthermore

\section{Elementary schools}

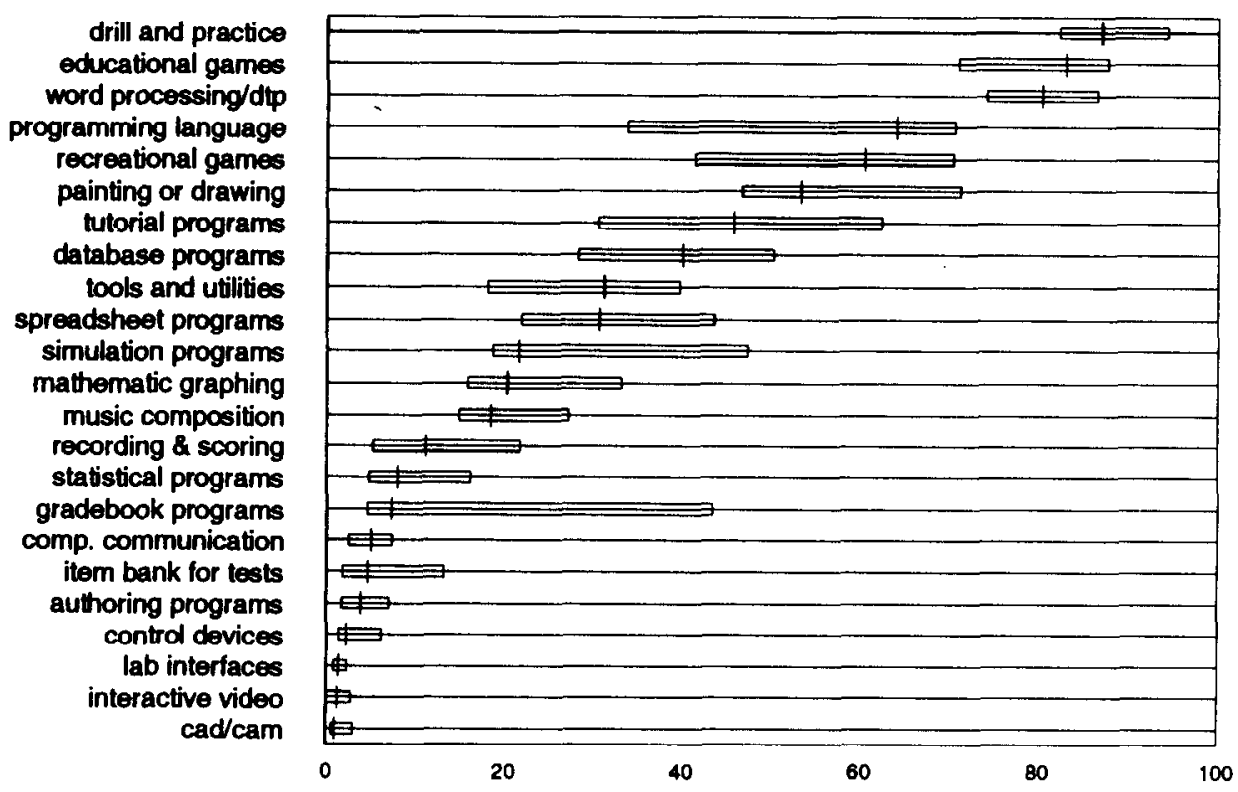

Fig. 1. Caption opposite. 
Lower secondary

word processing/dtp programming language

database programs spreadsheet programs drill and practice painting or drawing tutorial programs educational games recreational games mathernatic graphing tools and utilities simulation programs statistical programs gradebook programs comp. communication $\mathrm{cad} / \mathrm{cam}$ control devices music composition recording \& scoring authoring programs lab interfaces item banks for tests interactive video

$$
0
$$

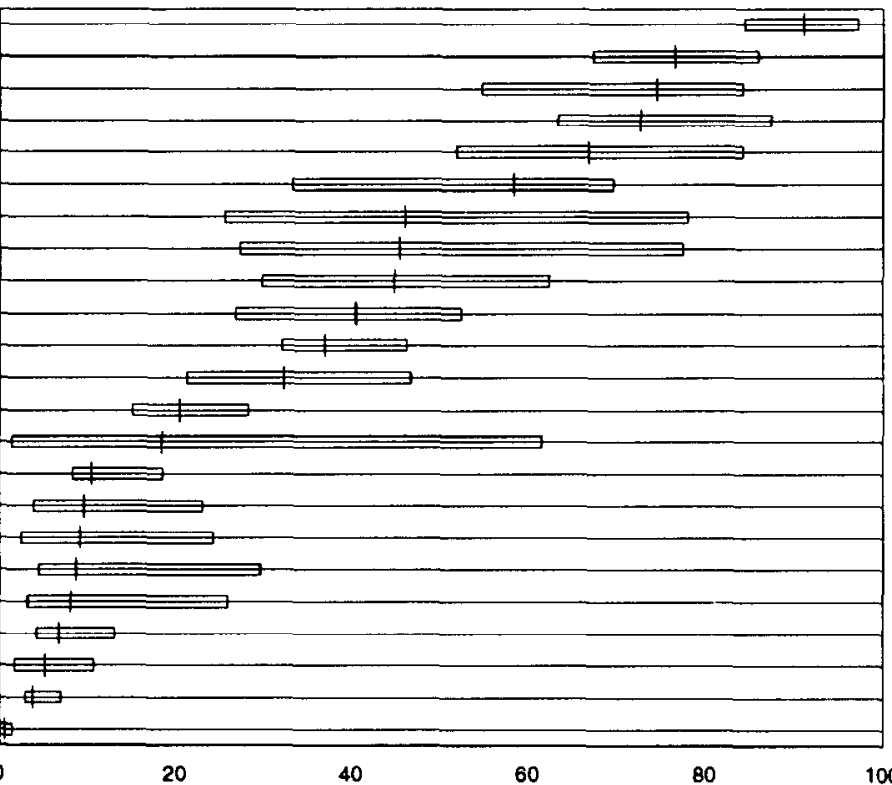

Upper secondary
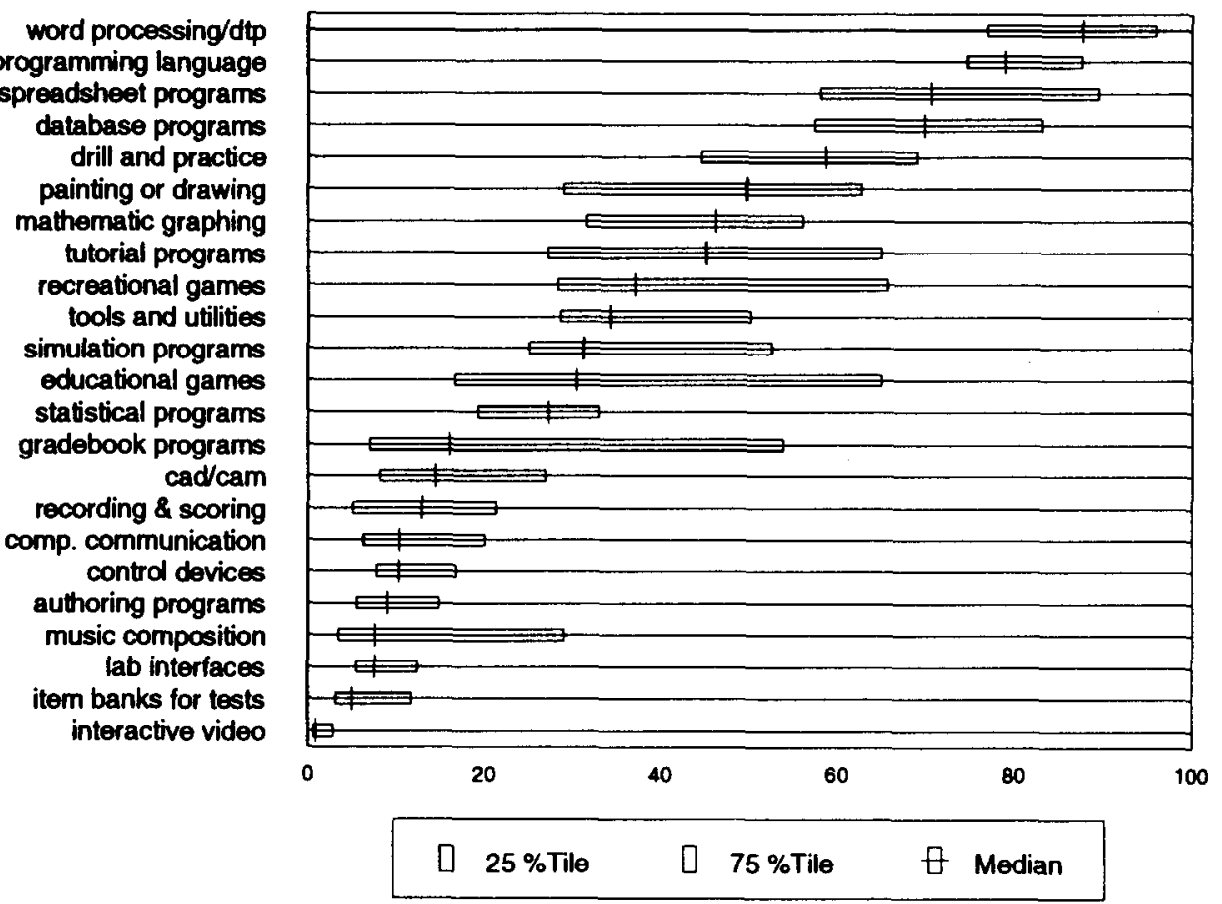

Fig. 1. Boxplots of country means of percentages of computer coordinators indicating that a particular type of software was available in their school.

it is quite interesting to note that item banks for testing students, a potentially very powerful application of computers, are hardly available in schools.

Principal component analysis of the ratings by computer coordinators of available software types results in clearly interpretable factors (Table 2): general purpose, learning, assessment, application and laboratory software.

The outcome reflects a distinction between software that is suited for learning with computers (factor 2) and software which tends more to be associated with learning about computers 
Table 2. Loadings for a 5-factor varimax solution of coordinators' ratings of available software

\begin{tabular}{|c|c|c|c|c|c|}
\hline \multirow[b]{2}{*}{ Software } & \multicolumn{5}{|c|}{ Factors } \\
\hline & 1 & 2 & 3 & 4 & 5 \\
\hline \multicolumn{6}{|l|}{ General purpose } \\
\hline Word processing & 0.67 & 0.22 & -0.05 & 0.06 & 0.07 \\
\hline Spreadsheet & 0.78 & 0.06 & 0.09 & 0.13 & 0.01 \\
\hline Database & 0.76 & 0.01 & 0.17 & 0.12 & 0.01 \\
\hline $\begin{array}{l}\text { Programming languages } \\
\text { Learning }\end{array}$ & 0.57 & 0.04 & -0.11 & 0.18 & 0.08 \\
\hline Drill and practice & 0.04 & 0.59 & 0.03 & 0.36 & 0.04 \\
\hline Tutorial programs & 0.10 & 0.45 & 0.22 & 0.34 & 0.06 \\
\hline Painting or drawing & 0.41 & 0.44 & 0.09 & 0.04 & 0.09 \\
\hline Music composition & 0.11 & 0.56 & 0.13 & -0.14 & 0.18 \\
\hline Recreational games & 0.08 & 0.69 & 0.04 & 0.05 & -0.04 \\
\hline Educational games & 0.04 & 0.72 & 0.14 & 0.18 & 0.02 \\
\hline \multicolumn{6}{|l|}{ Assessment } \\
\hline Item banks & 0.03 & 0.06 & 0.64 & 0.17 & 0.09 \\
\hline Record/score tests & 0.01 & 0.12 & 0.72 & 0.13 & 0.03 \\
\hline Grade book & 0.01 & 0.18 & 0.68 & 0.12 & 0.04 \\
\hline \multicolumn{6}{|l|}{ Application } \\
\hline Simulation & 0.14 & 0.34 & 0.14 & 0.48 & 0.19 \\
\hline Mathematics graphing & 0.30 & 0.20 & 0.00 & 0.62 & 0.06 \\
\hline Statistics & 0.14 & 0.06 & 0.21 & 0.59 & -0.00 \\
\hline CAI authoring & 0.11 & 0.04 & 0.22 & 0.56 & 0.03 \\
\hline \multicolumn{6}{|l|}{ Laboratory } \\
\hline Autom. data acquisition & -0.01 & -0.05 & -0.06 & 0.40 & 0.54 \\
\hline Control devices & 0.07 & 0.10 & -0.15 & 0.13 & 0.64 \\
\hline Control interact, video & -0.05 & 0.07 & 0.19 & -0.08 & 0.52 \\
\hline CAD/CAM & 0.23 & 0.05 & 0.30 & -0.07 & 0.45 \\
\hline Computer communication & 0.23 & 0.03 & 0.28 & 0.14 & 0.40 \\
\hline
\end{tabular}

Source: $[17]$.

(factor 1). The result of this factor analysis was used to create the scales: WITHSOFT, consisting of items which load higher than 0.44 on factor 2, reflecting the availability of software that is suited for learning with computers; and ABOUSOFT, consisting of the items with loadings $>0.44$ on factor 1 , reflecting the amount of software for learning about computers. The scores on each scale were standardized on a scale from 0 to 100 .

Figure 2 is the plot of country means for lower secondary schools on both scales. It shows that the country means for some countrics (New Zcaland, Canada-British Columbia, The Netherlands and France) are relatively high on both scales, whereas other countries are typically high on one type of software, for instance the USA is high on WITHSOFT, while Greece and Germany have

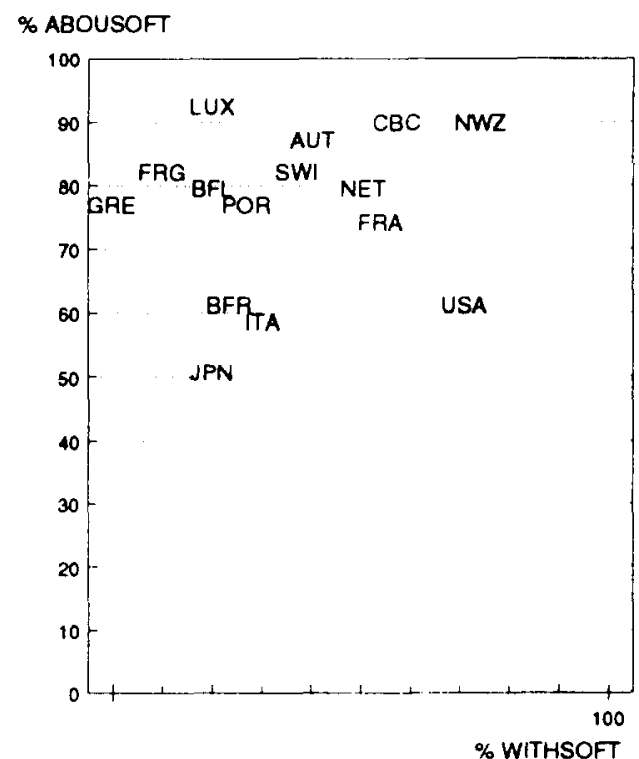

Fig. 2. Country positions for lower secondary schools on the standardized scales WITHSOFT (software for learning with computers) and ABOUSOFT (software for learning about computers). Abbreviated country names are listed on p. 324. 

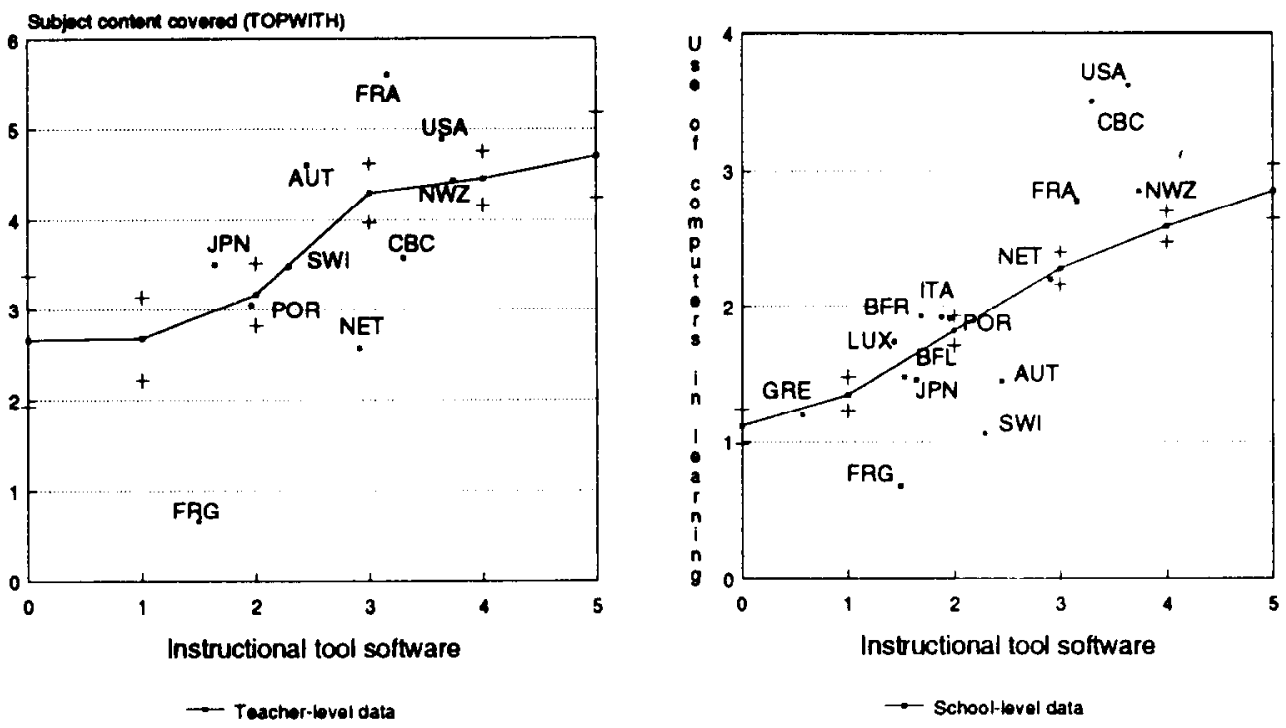

Fig. 3. Emphasis on learning with computers at school level and teacher level (TOPWITH) plotted against the availability of instructional tool software (software for learning) for lower secondary schools. Source: [17].

high scores on ABOUSOFT. The conditions for the integrated use in terms of the availability of instructional tool software in schools seems to be much better in some countries than in others. This may have positive effects on the degree of integration of computers. The tenability of such a hypothesis is confirmed by Fig. 3, which shows that emphasis on learning with computers at school level as well as on teacher level (TOPWITH, which is the number of subject topics for which computers are used) tends to be associated with the availability of instructional tool software in the schools. The country means also show this association quite clearly.

\section{Needs of educational practitioners}

The IEA Comped study provides some tentative answers to the question of needs of educational practitioners by examining the problems they are experiencing and what they see as high priorities.

All respondents (principals, computer coordinators, computer education-, mathematics-, science-, and mother tongue teachers) were asked to select from a list of 30 problems a maximum of five which they considered as most serious in using computers. Davis [10] summarizes the results as follows:

"... all staff saw basic infrastructure as the key problems: coordinators and teachers all rank insufficient computers and insufficient software as the two key problems. Principals rank them first and third. After these, principals and coordinators see teachers' lack of knowledge or skills about using computers in instruction as the key problem, while the teachers see lack of time to develop computer based lessons as the key problem".

These results show that a number of quite basic conditions (availability of materials, time and adequate staff development) don't seem to be fulfilled in a large number of schools. One may expect that these circumstances influence the way computers are used in schools, as we will describe in the next section.

\section{INTEGRATION OF COMPUTERS IN EDUCATION}

On basis of the data collected in the USA as part of the IEA-Comped study, Becker[12] states:

"In the last five years, changes in how schools use computers have been modest, but the direction that these changes are taking is fairly clear. Systematic and regular student practice of basic skills in elementary school computer laboratories has become somewhat more common. But the major development in computer activity at all levels, but primarily in middle and high schools, has been 

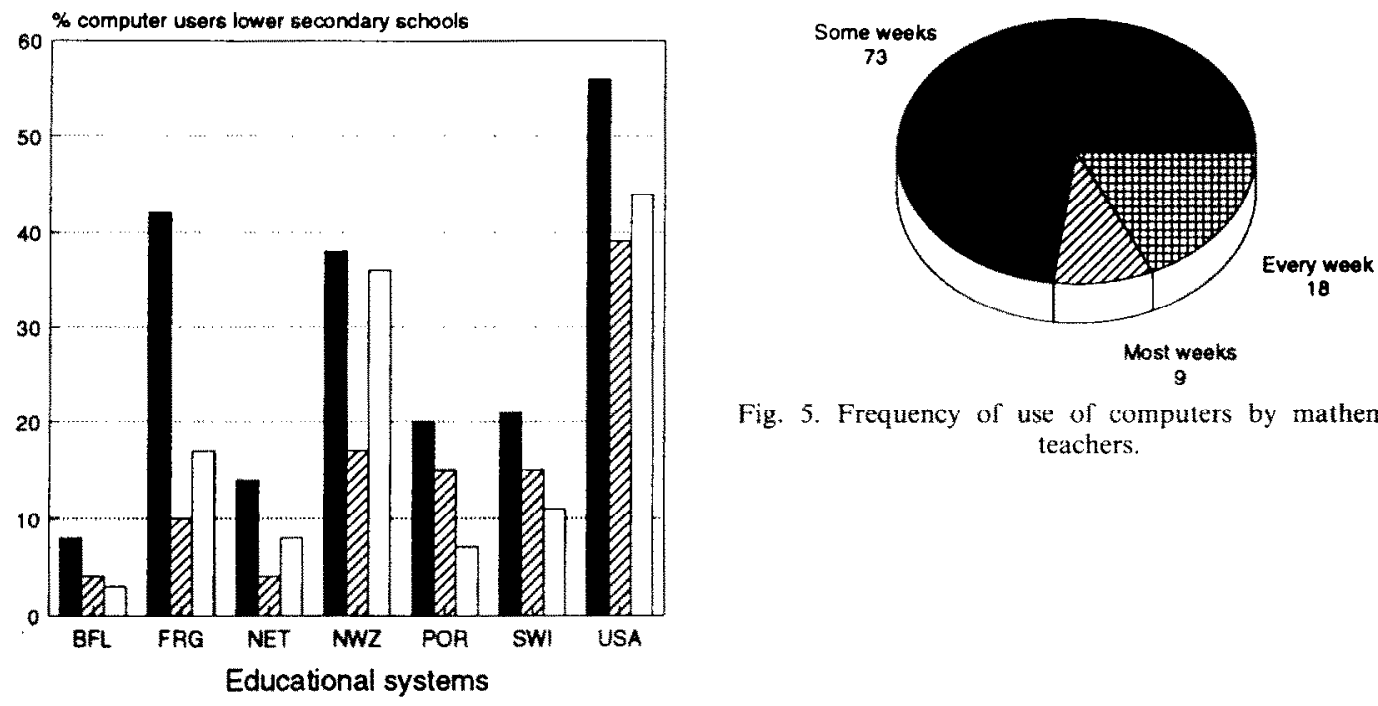

Fig. 5. Frequency of use of computers by mathemaics teachers.

Fig. 4. Per cent of computer using teachers in mathematics, science and mother torigue, according to school officials in computer-using schools.

a concentrated effort to use computers as productivity tools for expressing ideas and recording and analyzing information. Still, the progress in both directions has been slower than the adherents of either one would like to believe".

Although Becker is quite pessimistic about the status of computer integration in the curriculum, it should be noted (Fig. 3) that from a comparative point of view the USA is in a relatively good position with regard to computer integration. On the other hand, one should note that Fig. 3 is based on a rough indicator of computer integration and that at a more detailed level the picture is less positive. This can be illustrated with Fig. 4, which contains for a few countries in which these data could be collected, the probably inflated estimates of school officials as to the per cent of teachers using computers in mathematics, science and mother tongue and the frequency of computer use based on the ratings given by these computer-using teachers themselves.

From Fig. 4 one may infer that the per cent of teachers using computers is, in general, quite low and that the group of intensive computer using teachers, those who are using computers most or every week, will at the best not exceed $15 \%$. It probably is even worse than that, as deeper analyses show that "the proportion of exemplary teachers (i.e. teachers who integrate computers to a substantial extent) among all teachers of the studied subjects (Mathematics, Science, Mother Tongue) and grade levels is only 3\%"[13].

If we could agree that the most promising development regarding the future of educational computer use would be the full integration of computers in education, the question arises how this goal may be achieved. To shed some light on this question, one needs to understand the role of the different factors in the implementation process and how these factors interact. As was shown in the previous sections, the degree of integration of computers in education covaries in a meaningful way with other variables, like the availability of software, etc. However, one should be aware that covariation does not mean that one variable is influencing the other in a causal way. Recently, some quite powerful techniques have been developed to examine the causal relations of all variables together. Although these techniques still offer no final proof, which only can be derived from real controlled experiments in education, it has the advantage that it offers a very good statistical test of a hypothesized causal model. Although space consideration prevent to provide an in-depth description of the results of these causal analyses (we refer the interested reader to [14]), we will mention here some of the main findings.

Figure 5 shows a model that fits the Germany data. It shows that the degree of implementation of computers in Germany is influenced by a number of factors. Of direct influence are teacher 


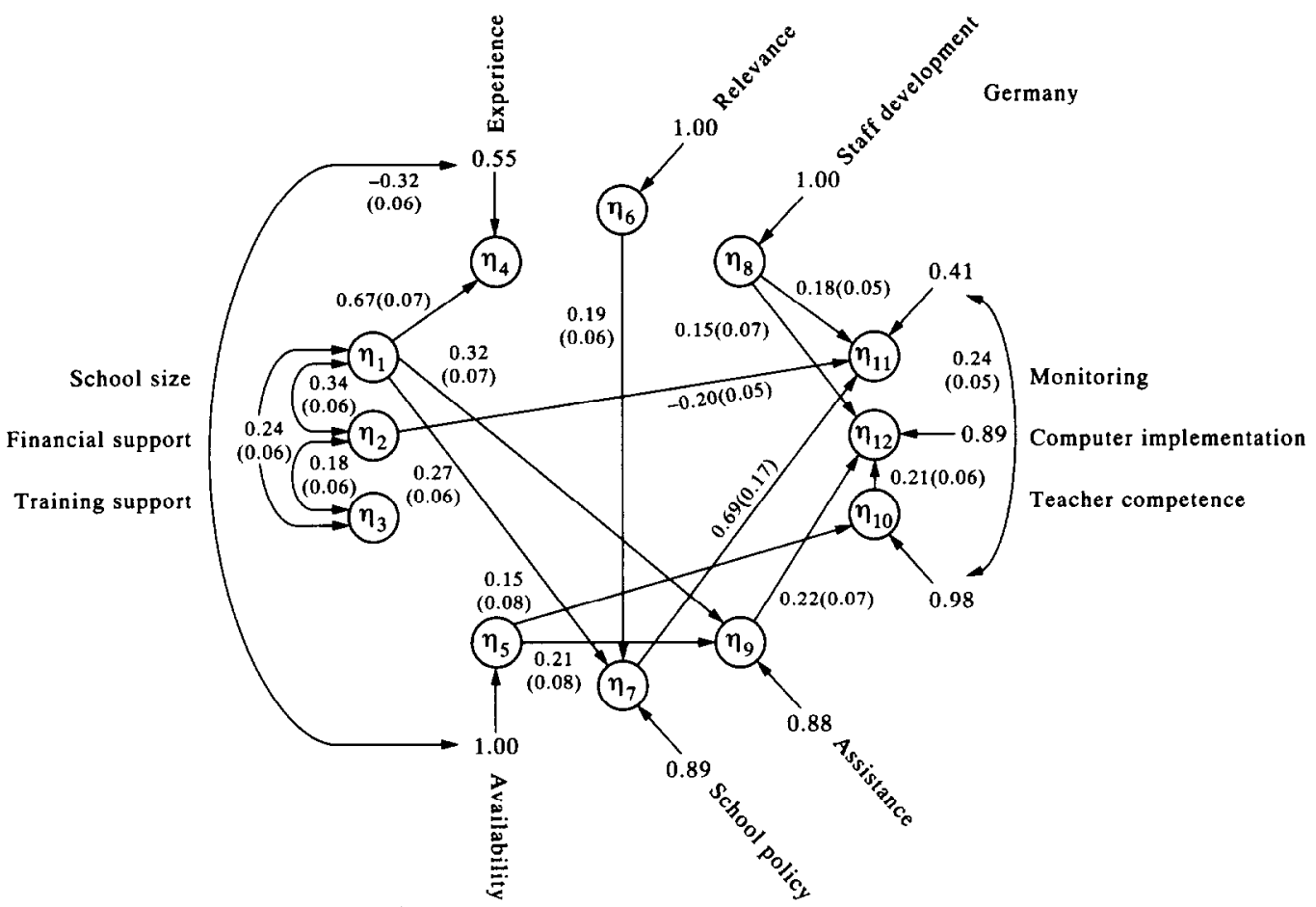

Fig. 6. Standardized effects on innovation strategy and computer implementation for lower secondary schools in Germany (standard errors in parentheses) - reproduced from Brummelhuis and Tuijnman[14].

competence, staff development and internal assistance for innovation. Of more indirect influence are availability of computers and school size. After analysing the results from other countries, it was found that teacher skills especially are very important in determining to what extent computers are used in the curriculum. Given this importance, we summarize in the next section the main findings from the IEA-Comped study with regard to staff development.

\section{STAFF DEVELOPMENT}

Staff development might not be the only contributor to the integration of the computer in existing subject areas, but it is an important factor to look at [15]. An analysis of the number of years teachers work with the computer for instructional purposes and the degree of computer integration shows that more integration of the computer can be expected when a teacher works longer with the computer. Apparently, computer integration is such a complex innovation that it cannot be expected to be fully implemented within a short period of time.

\section{CONCLUSIONS}

The results from the IEA-Comped study show that there is reason for optimism as well as pessimism regarding the fate of computers in education. The optimistic view is that computers are now available for many schools in most so-called developed countries, and that despite the complexity of this innovation educational practitioners and students are still very enthusiastic about the technology. Despite the many school administrators and teachers who feel overburdened by the extra demands on their time for educational computer use, it is remarkable that many are willing to invest additional time to become acquainted with it or as one of the teachers said: "It costs so much time. If students were not so enthusiastic we would already have given up".

On the other side, one should note that there is still inequity of access to computers. Some countries lag far behind in terms of the availability of computers in schools. Moreover, once computers are available they tend to be used most frequently as an add-on to the existing curriculum, rather than as productivity tools which may enhance the quality of education. It is probably this lack of integration of computers in existing curricula, which is most challenging in 
determining our agenda for the future, or as Anderson and Collis[16] stated: "... we believe that the 'functionality' perspective will prove to be the most useful for policy' and planning in the future".

As pointed out already, there are several perspectives or models regarding the goals of computer use. A main distinction is between learning about computers (the technical model) and learning with computers (the integration model or the functionality perspective).

The evolution of these models can be seen as a typical product of the $1980 \mathrm{~s}$. In the early $1980 \mathrm{~s}$ computer hardware and software characteristics were such that "... one often had to write a program in BASIC, FORTRAN or Pascal to accomplish a computer related task"[16]. Later, in Northern America and Western Europe the concern for integration grew, which also may be interpreted as a kind of opportunistic reaction to the increased hardware and software capabilities, while in many Eastern European countries the technical model was the official one.

The distinction between these main models is also clearly reflected in the data, as the principal component analyses showed. There was a main distinction between learning about computers and learning with computers. In many countries there is an emphasis on learning about computers, while some countries are relatively far ahead with integrating computers in the curriculum. The USA is heading this development, as was illustrated, for example, in Fig. 3. However, some caution is required in interpreting this result, as more in-depth analyses showed that "the proportion of exemplary teachers (that is, teachers who integrate computers to a substantial extent: WJP/TP) among all teachers of the studied subjects (Mathematics, Science. Mother Tongue: WJP/TP) and grade levels is only 3\%"[13]

The question arises why some schools and teachers integrate computers to a greater extent than others. Figure 6 illustrated how this question might be answered, in showing that many factors play a role, but, "The highest degree of confirmation for the influence of indicators on computer use among countries was found for internal innovation assistance and teacher competence and readiness" [14]. A recent paper of Becker[13], using a different analysis technique confirms this finding for the USA: "Exemplary teachers teach in an environment that helps them to be better computer using teachers, they are themselves better prepared to use computers well in their teaching". The section on staff development (more extensively described by Janssen Reinen and Plomp[15] illustrates how our insight in the issue of staff development can be further deepened.

\section{REFERENCES}

1. Hawkridge D, Computers in third world schools: the example of China. Br. I Fdur. Technol. 21, 4-20 (1990)

2. Makau B. M., Computers in Kenya's Secondary Schools: Case Study of an Innovation in Education. IDRC, Ottawa (1990).

3. Pelgrum W. J. and Plomp Tj., The Use of Computers in Education Worldwide: Results from the IEA 'Computers in Education' Survey in 19 Education Systems. Pergamon Press, Oxford (1991).

4. Plomp Tj. and Pelgrum W. J., Introduction of computers in education: state of the art in eight countries. Computers Educ. 17, 249-258 (1991).

5. Hayes W. A., IEA Guidebook 1991: Activities Institutions and People. Pergamon Press, Oxford (1991).

6. Passow A. H., Noah H. J., Eckstein M. A. and Mallea J. R., The National Case Study: An Empirical Comparative Study of Twenty-one Educational Systems. Almqvist \& Wiksell, Stockholm (1976).

7. Husen T. and Postlethwaite T. N. (Eds), The International Encylopedia of Education. Pergamon Press, Oxford (1985).

8. Fullan M. G., Miles M. B. and Anderson S. E.. Strategies for Implementing Microcomputers in Schools: the Ontario Case. Ministry of Education, Ontario (1988).

9. Fullan M. G. and Stiegelbauer S., The Meaning of Educational Change. Teachers College Press, New York (1991).

10. Davis D., Educational uses of computers. In Computers in Education: Implementation of an Innovation in 20 Countries (Edited by Pelgrum W. J. and Plomp Tj.). In press (1993).

11. Walker D. F., Computers and the curriculum. In Microcomputers and Education: Eighty-fifih Yearbook of the National Society for the Study of Education (Edited by Culbertson J. A. and Cunningham L. L.). University of Chicago Press, Chicago, Ill. (1986).

12. Becker H. J., Computer use in the United States schools: 1989. An initial report of U.S. participation in the I.E.A. Computers in Education Survey. Paper presented at the 1990 meeting of the American Educational Research Association (1990).

13. Becker H. J., How our best computer using teachers differ from other teachers: implications for realizing the potential of computers in schools. Paper presented at the AERA Conference, San Francisco (April 1992).

14. ten Brummelhuis A. C. A. and Tuijnman A. C., Factors determining the degree of computer implementation: a comparison between six educational systems. Paper presented at the European Conference on Educational Research. Enschede, The Netherlands (June 1992).

15. Janssen Reinen I. A. M. and Plomp Tj, Staff development as condition for computer integration. Paper presented at the AERA Conference, San Francisco (April 1992).

16. Anderson R. E. and Collis B., International assessment of functional computer abilities. Paper presented at the AERA Conference, San Francisco (April 1992).

17. Pelgrum W. J. and Schipper A. T., Indicators of computer integration in education. Computers Educ. In press (1993). 